Preface

\title{
The Complexity of Trauma-Induced Coagulopathy
}

\author{
Hunter B. Moore, MD, PhD ${ }^{1}$ Mark Walsh, MD²,3 \\ Robert L. Medcalf, PhD ${ }^{5}$ \\ ${ }^{1}$ Department of Surgery, University of Colorado School of Medicine, \\ Denver, Colorado \\ 2 Department of Emergency Medicine, Saint Joseph Regional Medical \\ Center, Mishawaka, Indiana \\ ${ }^{3}$ Department of Internal Medicine, Saint Joseph Regional Medical \\ Center, Mishawaka, Indiana \\ ${ }^{4}$ Division of Hematology and Oncology, Department of Medicine, \\ Feinberg School of Medicine, Northwestern University, Chicago, \\ Illinois \\ ${ }^{5}$ Molecular Neurotrauma and Haemostasis Laboratory, Australian \\ Centre for Blood Diseases, Monash University, Victoria, Australia
}

Semin Thromb Hemost 2020;46:114-115.

Trauma-induced coagulopathy (TIC) is a complex process that, to date, remains poorly understood. The appreciation of the limitation of using conventional coagulation assays to assess hemostasis in trauma has led to an explosion of research in the field. Emerging data now support the need to look outside the convention coagulation box and look for injury-specific mechanisms that change coagulation following injury and hemorrhagic shock due to the close connection of the coagulation system with the central nervous system, immune system, and cardiovascular system. This edition of Seminars of Thrombosis and Hemostasis is intended to highlight the divergent area of research in the field and the ongoing need for further translational efforts.

TIC is present in a high percentage of very severely injured trauma patients upon presentation. While the historic definitions of TIC dichotomized patients as having coagulopathy based on prothrombin time (or international normalized ratio [INR]), a more complex understanding of this pathophysiology has evolved. The coagulation system following trauma has derangements that include thrombin generation and dysfunction of platelets, fibrinogen, the fibrinolytic system, and the innate immune system. None of these derangements are reliably measured with an INR.

This issue starts with a discussion of the pathophysiology of coagulation activation and fibrinolysis in trauma from a hematologist's perspective and postulates that fibrinolysis plays the central role. ${ }^{1}$ This is followed by a review on the specific roles of platelets and fibrinogen in TIC by St. John and White. ${ }^{2}$ Hartman et al then provided an in-depth description of viscoelastic methods involving the thromboelastography and rotational thromboelastometry. ${ }^{3}$

Trauma creates a broad spectrum of abnormal physiology, with a wide range of tissue injury and blood pressures ranging from hypertensive to asystole. Therefore, it is not surprising that a spectrum of coagulation changes is present when these severely injured patients present to the emergency department. To add complexity to the understanding of TIC, specific organ injury and the age of the trauma patient appear to drive different changes in coagulation. The similarity and differences between adults and pediatric trauma patients are presented by Lucisano et al. ${ }^{4}$

Emerging literature also supports a link between changes in coagulation and fibrinolysis, and the central nervous, cardiovascular, and innate immune systems. The changes in traumatic brain injury are reviewed by Maegele et $\mathrm{al}^{5}$ whereas Zhao et al discuss the role of mitochondria in brain injury. 6

There are also differences in organ-specific contributions to coagulopathy, requiring ongoing investigation to better understand the pathophysiology of TIC. Combining all trauma patients into one category of TIC will provide a limitation in understanding the complete picture of what drives coagulopathic bleeding and mortality in affected patients. This includes the feedback between coagulation and the other systems. The fibrinolytic system, for example, appears to have direct communication with complement activation and adaptive immunity following injury, as discussed by Medcalf et al. ${ }^{7}$ Many of these changes can be modified with antifibrinolytics such as
Address for correspondence Hau C. Kwaan, MD, FRCP, Division of Hematology and Oncology, Department of Medicine, Feinberg School of Medicine, Northwestern University, Room 8258, Olson Pavilion. 710 North Fairbanks Court, Chicago, IL 60611

(e-mail: h-kwaan@northwestern.edu).
Issue Theme The Complexity of Trauma-Induced Coagulopathy; Guest Editors: Hau C. Kwaan, MD, FRCP, Hunter B. Moore, MD, PhD, Robert L. Medcalf, PhD, and Mark Walsh, MD.
Copyright $\odot 2020$ by Thieme Medical Publishers, Inc., 333 Seventh Avenue, New York, NY 10001, USA. Tel: +1(212) 760-0888.
DOI https://doi.org/ 10.1055/s-0040-1702202. ISSN 0094-6176. 
tranexamic acid (TXA), and the basis for its use is further discussed by Barrett et al, ${ }^{8}$ who also propose that antifibrinolytic agents may have additional effects beyond their intended hemostatic use.

One of the largest limitations in our current understanding of TIC is using a single time point to define the patients' projected outcome. However, the coagulation system is dynamic and can change within minutes after resuscitation. A general theme of the existing limited literature on the dynamic changes in coagulation following injury suggests that hypocoagulable trauma patients will transition to a hypercoagulable state following resuscitation in 12 to 24 hours. However, specific components of the coagulation system such as fibrinolysis may be impaired by the time the trauma patients present to the hospital. Observation of such changes is presented by Moore and Moore. ${ }^{9}$ Addressing the hypercoagulable component of TIC is equally as important as addressing the hypocoagulable component, as delayed mortality in trauma patients is often attributable to thrombotic complications and organ failure. Dobson et al therefore give their view on the systems failure in the early stages of trauma. ${ }^{10}$

Treatment of TIC also remains controversial. The current management is institution-dependent and often not initiated based on the patient's coagulation status. Bleeding trauma patients in the emergency department get lumped into a massive transfusion protocol that is not based on their coagulation status, and empiric blood products are administered. Waiting for coagulation assessment is often not clinically feasible in these actively bleeding patients as an INR can take 40 minutes to obtain results, and viscoelastic testing indices range from 5 to 60 minutes, depending on the coagulation variable being measured. Treatment begins with ratiodriven resuscitation of red blood cells and plasma, which are given at a ratio of at least 2:1 with augmentation of platelets and cryoprecipitate after more than 6 units of products have been administered. Some institutions continue this ratio driven resuscitation, whereas others use point-of-care testing with viscoelastic assays to target blood product administration over time. An emerging old concept is the utilization of whole blood for resuscitation in trauma. Early nonrandomized trial data supports favorable results, as presented by Black et $\mathrm{al}^{11}$ but this empiric transfusion strategy remains as controversial as the use of TXA in trauma, with different institutions having polarizing opinions of its perceived benefit. This aspect is discussed by Walsh et al. ${ }^{12}$

We believe that the articles presented in this issue of Seminars of Thrombosis and Hemostasis will provide updated information on the complex topic of TIC and will be of much interest to clinicians and scientists in this rapidly growing field.

\section{Conflict of Interest}

None declared.

\section{ReferencesReferences}

1 Kwaan HC. The central role of fibrinolytic response in trauma induced coagulopathy - a hematologist's perspective. Semin Thromb Hemost 2020;46(02):116-124

2 St. John AE, White NJ. Platelets and fibrinogen: emerging complexity in trauma-induced coagulopathy. Semin Thromb Hemost 2020;46(02):125-133

3 Hartmann J, Walsh M, Grisoli A, et al. Diagnosis and treatment of trauma-induced coagulopathy by viscoelastography. Semin Thromb Hemost 2020;46(02):134-146

4 Lucisano AC, Leeper CM, Gaines BA. Trauma induced coagulopathy in children. Semin Thromb Hemost 2020;46(02):147-154

5 Maegele M, Aversa J, Marsee MK, McCauley R, Chitta H, Vyakaranam S, Walsh $M$. Changes in coagulation following brain injury. Semin Thromb Hemost 2020;46(02):155-166

6 Zhao Z, Zhou Y, Li M,Zhang J, Dong J. Extracellular mitochondria in traumatic brain injury-induced coagulopathy. Semin Thromb Hemost 2020;46(02):167-175

7 Medcalf RL, Keragala C, Draxler DF. Fibrinolysis and the immune response in trauma. Semin Thromb Hemost 2020;46(02): 176-182

8 Barrett CD, Kong YW, Yaffe MB. Influence of tranexamic acid on inflammatory signaling in trauma. Semin Thromb Hemost 2020; 46(02):183-188

9 Moore HB, Moore EE. Temporal changes in fibrinolysis following injury. Semin Thromb Hemost 2020;46(02):189-198

10 Dobson GP, Morris JL, Davenport LM, Letson HL. Traumaticinduced coagulopathy as a systems failure: a new window into hemostasis. Semin Thromb Hemost 2020;46(02):199-214

11 Black JA, Pierce VS, Kerby JD, Holcomb JB. The evolution of blood transfusion in the trauma patient: whole blood has come full circle. Semin Thromb Hemost 2020;46(02):215-220

12 Walsh M, Fries D, Moore EE. Whole blood for civilian urban trauma resuscitation: historical, present, and future considerations. Semin Thromb Hemost 2020;46(02):221-234 